\title{
Silos experimentais para avaliação da silagem de três genótipos de girassol (Helianthus annuus L.)
}

[Evaluation of sunflower (Helianthus annuus L.) silage of three genotypes as affected by experimental silos]

\author{
L.G.R. Pereira ${ }^{1}$, L.C. Gonçalves ${ }^{2}$, T.R. Tomich ${ }^{3}$, I. Borges ${ }^{2}$, N.M. Rodriguez ${ }^{2}$ \\ ${ }^{1}$ Departamento de Ciências Agrárias e Ambientais da Universidade Estadual de Santa Cruz \\ Rod. Ilhéus-Itabuna, km 16, Salobrinho \\ 45650-000 - Ilhéus, BA \\ ${ }^{2}$ Escola de Veterinária da UFMG - Belo Horizonte, MG \\ ${ }^{3}$ Embrapa Pantanal - Corumbá, MS
}

\begin{abstract}
RESUMO
Três tipos de silos experimentais foram utilizados para a avaliação das silagens de três genótipos de girassol: $A$ ) silo padrão com válvula de Bunsen; $B$ ) silo dotado de compartimento para efluentes e $C$ ) silo com válvula de Bunsen e compartimento para efluentes. O delineamento experimental foi inteiramente ao acaso, em esquema fatorial $3 \times 3$ (genótipos $\times$ tipos de silos) com três repetições. As características

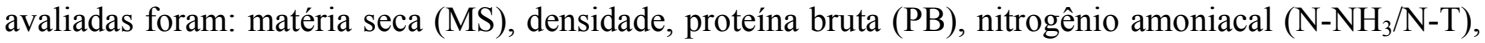
$\mathrm{pH}$, carboidratos solúveis (CHO), ácidos orgânicos, constituintes da parede celular, extrato etéreo (EE) e digestibilidade in vitro da matéria seca (DIVMS). As silagens obtidas nos silos $B$ e $C$ apresentaram os maiores valores de MS e menores de $\mathrm{NH}_{3} / \mathrm{N}-\mathrm{T}$. Os valores de $\mathrm{pH}$ se equivaleram nos três tipos de silos, enquanto os teores de $\mathrm{CHO}$ foram menores para as silagens obtidas nos silos $B$ e $C$. Os silos dotados de compartimento para efluentes apresentaram os maiores valores de ácido láctico. As frações fibrosas, EE e DIVMS não sofreram influência dos tipos de silos. A presença ou ausência da válvula de Bunsen não influenciou os parâmetros avaliados. A presença do compartimento para efluentes afetou a qualidade e o valor nutritivo da silagem de girassol.
\end{abstract}

Palavras-chave: girassol, efluente, fermentação, silagem, tipo de silo

\begin{abstract}
A completely randomized design in a $3 \times 3$ factorial scheme was used to evaluate the effect of three genotypes and three types of silos on sunflower silage. The silos were: A- silo with Bunsen valve; $B$ - silo with effluent-collecting equipment; and C- silo with both Bunsen valve and effluent-collecting equipment. The parameters evaluated were: dry matter (DM), crude protein (CP), ammonia nitrogen $\left(\mathrm{N}-\mathrm{NH}_{3} / \mathrm{T}-\mathrm{N}\right)$, pH, soluble carbohydrates (CHO), organic acids, cell wall constituents, ether extract and in vitro dry matter digestibility (IVDMD). The silage from silos $\mathrm{B}$ and $\mathrm{C}$ had higher values of DM and lower levels of $\mathrm{N}-\mathrm{NH}_{3} / \mathrm{T}-\mathrm{N}$. The $\mathrm{pH}$ value was the same for all silos, while the CHO was the same for silos $\mathrm{B}$ and $\mathrm{C}$. Sunflower silage from silos with effluent-collecting equipment showed higher values of lactic acid. For fibrous fractions, EE and IVDMD, no effect of silo type was found. The Bunsen valve had no effect on the measured parameters. However, the effluent-collecting equipment affected both the quality and nutritive value of sunflower silage.
\end{abstract}

Keywords: sunflower, effluent, fermentation, silage, silo type

Recebido para publicação em 29 de julho de 2003

Recebido para publicação, após modificações, em 31 de maio de 2004

E-mail: luizgustavo@uesc.br 


\section{INTRODUÇÃO}

A mais antiga descrição de produção de silagem, de 1842, é de autoria de Grieswald e foi publicada no "Transactions of the Baltic Association for the Advancement of Agriculture" (McDonald at al., 1991). Desde então, as transformações bioquímicas que as forragens sofrem do momento da ensilagem até a obtenção do produto final são alvos de pesquisadores no mundo inteiro.

São muitos os fatores que influem na qualidade da silagem, o que torna praticamente impossível os estudos em silos convencionais de fazenda (Hargreaves et al., 1986). Assim, esforços são destinados à busca de silos de laboratório que permitam o máximo controle dos fatores que interferem nos processos fermentativos. O emprego de silo de laboratório oferece grande facilidade de manipulação, e as fermentações são comparáveis às dos silos convencionais e, como o volume de material ensilado é reduzido, os trabalhos podem ser feitos a baixo custo, com maior número de variáveis e repetições (Perkins e Pratt, 1951).

O menor ciclo de produção, a resistência ao frio e a elevada capacidade de extrair a água no solo são características que habilitam o girassol como opção para produção de silagens na época da safrinha ou em locais onde a deficiência hídrica impossibilita o cultivo de outras culturas tradicionais, como o milho e o sorgo (Tomich at al., 2003). As silagens de girassol apresentam baixos conteúdos de MS, conforme dados da tabela brasileira de composição de alimentos para bovinos (Valadares Filho et al., 2002), que indica valor médio de $23,5 \%$.

Os silos de laboratório utilizados na avaliação de silagem de girassol geralmente são confeccionados com tubos de PVC, apresentam válvula do tipo Bunsen para o escape dos gases, mas não possibilitam o escoamento de efluentes, pois apresentam o fundo completamente vedado (Freire, 2001; Rezende, 2001; Tomich at al., 2003).

A presença de efluente dentro do silo é indesejável e deve ser evitada para não ocorrer prejuízo no processo fermentativo, tal como o aumento da proteólise e o estabelecimento de bactérias clostrídicas (Elferink at al., 2000).
Assim, em experimentos que avaliem a ensilagem de forragens com alto conteúdo de umidade, a presença de efluente no silo de laboratório pode alterar a qualidade da silagem.

O objetivo deste trabalho foi avaliar a qualidade final das silagens de três genótipos de girassol obtidas em três tipos de silos de laboratório que continham ou não compartimento para escape de efluentes e válvula do tipo Bunsen para o escape de gases.

\section{MATERIAL E MÉTODOS}

A variedade de girassol V2000 e os híbridos M737 e Contiflor 3 foram cultivados, colhidos e ensilados na Embrapa Milho e Sorgo, no município de Sete Lagoas-MG.

O corte das plantas foi efetuado manualmente, rente ao solo, quando essas apresentavam acima de $90 \%$ dos grãos maduros, sendo imediatamente picadas em partículas de aproximadamente dois centímetros, ensiladas e compactadas com auxílio de um êmbolo de madeira em três tipos de silos de laboratório, conforme Fig. 1. O silo A (padrão) é dotado de válvula do tipo Bunsen. No $\mathrm{B}$, há um compartimento inferior contendo areia esterilizada, separada por tela de náilon da área útil que recebeu o material ensilado. $\mathrm{O}$ silo $\mathrm{C}$ é semelhante, mas dotado de válvula do tipo Bunsen.

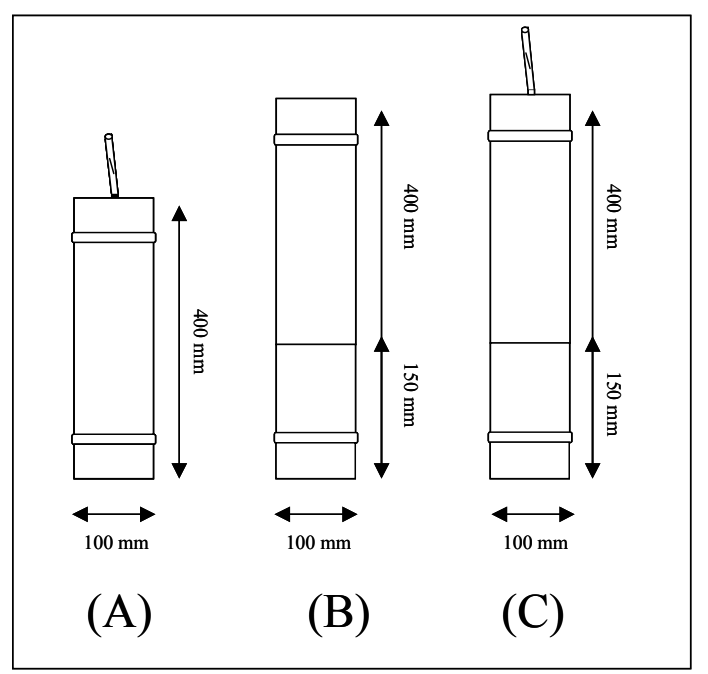

Figura 1. Tipos de silos de laboratório utilizados para avaliação das silagens de girassol. 
Para estimar a densidade da silagem, os silos foram pesados antes e depois da colocação da forragem. Foram ensilados três genótipos de girassol, em três tipos de silos, com três repetições cada, totalizando 27 silos. Para estimar a densidade da silagem, relacionou-se o peso do material ensilado com a área ocupada pela forragem no silo. Após 56 dias de fermentação, os silos foram abertos, seguindo a retirada e a homogeneização do seu conteúdo. Uma parte foi amostrada e seca em estufa de ventilação forçada a $65^{\circ} \mathrm{C}$ até peso constante, enquanto a outra porção foi utilizada para a extração do "suco" da silagem, utilizando-se prensa hidráulica.

Para avaliações do $\mathrm{pH}$, do nitrogênio amoniacal em relação ao nitrogênio total $\left(\mathrm{N}-\mathrm{NH}_{3} / \mathrm{NT}\right)$ e dos ácidos orgânicos - lático (LAT), acético (ACE) e butírico (BUT) - determinados no suco da silagem, e avaliações da matéria seca (MS), da proteína bruta $(\mathrm{PB})$, das frações fibrosas - fibra em detergente neutro (FDN), fibra em detergente ácido (FDA), hemicelulose, ceulose e lignina dos carboidratos solúveis $(\mathrm{CHO})$ e da digestibilidade in vitro da matéria seca (DIVMS), avaliados no material pré-secado em estufa de ventilação forçada a $65^{\circ} \mathrm{C}$ e moídos a $1 \mathrm{~mm}$, foram adotadas as recomendações de rotina para experimentos dessa natureza (Tilley e Terry, 1963; Bailey, 1967; Van Soest et al., 1991; Official... 1995).

Foi empregado um delineamento experimental inteiramente ao acaso, em esquema fatorial $3 \times 3$ (genótipos $\times$ tipos de silos) com três repetições. Os dados foram analisados segundo o modelo estatístico

$Y_{i j k}=\mu+G_{i}+S_{j}+G^{*} S_{i j}+e_{i j k}$, em que:

$\mathrm{Y}_{\mathrm{ijk}}=$ observação $k$ no genótipo $i$ submetido ao tipo de silo $j$;

$\mu=$ média geral;

$\mathrm{G}_{\mathrm{i}}=$ efeito do genótipo $\mathrm{i}, \mathrm{i}=1,2,3$;

$\mathrm{S}_{\mathrm{j} \mathrm{k}}=$ efeito do tipo de silo $\mathrm{j}, \mathrm{j}=1,2,3$;

$\mathrm{G} * \mathrm{~S}_{\mathrm{ij}}=$ efeito da interação do genótipo i com o tipo de silo j;

$\mathrm{e}_{\mathrm{ij}}=$ erro experimental.

Para a comparação das médias, foi empregado o teste SNK a 5\% de probabilidade.

\section{RESULTADOS E DISCUSSÃO}

Na Tab. 1 são apresentados os valores de MS das silagens dos três genótipos de girassol obtidos nos três tipos de silos. Os valores oscilaram de $19,8 \%$ para a silagem do genótipo M737 a 25,8\% para a silagem do V2000, ambas obtidas no tipo de silo A. Na comparação entre genótipos, notam-se os maiores valores para o genótipo V2000, seguido do Contiflor 3 e M737 $(\mathrm{P}<0,05)$ em todos os tipos de silos, exceção feita para as silagens obtidas no tipo de silo $\mathrm{C}$, em que os valores de MS do V2000 e do Contiflor 3 foram semelhantes $(\mathrm{P}>0,05)$. Houve diferenças nas médias de MS das silagens produzidas nos silos tipo A quando comparadas com os valores das silagens dos silos $\mathrm{B}$ e $\mathrm{C}$, que se equivaleram e superaram o silo A para os genótipos M737 e Contiflor 3. O valor de MS do genótipo V2000 não foi influenciado pelo tipo de silo.

Tabela 1. Teores de matéria seca (\%) das silagens de três genótipos de girassol obtidos em três tipos de silos experimentais

\begin{tabular}{lcccc} 
Silo & V2000 & M737 & Contiflor 3 & Média \\
\hline $\mathrm{A}$ & $25,76 \mathrm{Aa}$ & $19,75 \mathrm{Bc}$ & $22,99 \mathrm{Bb}$ & 22,83 \\
$\mathrm{~B}$ & $25,59 \mathrm{Aa}$ & $21,03 \mathrm{Ac}$ & $24,66 \mathrm{Ab}$ & 23,63 \\
$\mathrm{C}$ & $25,09 \mathrm{Aa}$ & $21,27 \mathrm{Ab}$ & $24,77 \mathrm{Aa}$ & 23,84 \\
Média & 25,48 & 20,68 & 24,14 & \\
\hline
\end{tabular}

Valores seguidos por letras maiúsculas distintas na mesma coluna ou letras minúsculas distintas na mesma linha diferem entre si $(\mathrm{P}<0,05) ; \mathrm{CV}=1,6 \%$; interação: tipo de silo $\times$ genótipo $(\mathrm{P}<0,05)$.

Os resultados obtidos estão próximos aos observados por Rezende (2001), que obteve valor médio de $22,7 \%$ de MS para seis genótipos ensilados após 95 dias do plantio. As diferenças observadas entre os tipos de silos devem-se à presença do compartimento para o escoamento de efluentes. Para o V2000, essas diferenças não foram observadas, o que provavelmente está relacionado ao seu mais elevado conteúdo de MS, o qual teria impedido a produção de quantidades de efluentes que escoassem para o compartimento com areia e modificassem os teores de MS da silagem. Segundo Xiccato et al. (1994), as perdas por efluentes são pequenas, quando a MS da forragem é superior a $25 \%$, e sua produção virtualmente cessa com $29 \%$ de MS. 
O conteúdo de MS da silagem é considerado o fator mais importante no processo de ensilagem (McDonald et al., 1991). Assim, a presença dos efluentes dentro dos silos e a conseqüente modificação no conteúdo de MS da massa ensilada podem alterar o curso dos processos fermentativos durante a ensilagem, afetando a sua qualidade e favorecendo o crescimento de bactérias clostrídicas, aumentar a proteólise e modificar o perfil de produção de ácidos orgânicos.

Os valores de densidade (dados não tabulados) oscilaram de $762,9 \mathrm{~kg} / \mathrm{m}^{3}$, para o genótipo V2000 no silo $\mathrm{C}$, a $846,9 \mathrm{~kg} / \mathrm{m}^{3}$, para o $\mathrm{M} 737$ no silo $\mathrm{B}$, e são condizentes com os observados na literatura para silagens de girassol, obtidas em silos de laboratório confeccionados com tubos de PVC (Freire, 2001; Tomich et al., 2003). A interação entre genótipo e tipo de silo não foi significativa $(\mathrm{P}>0,05 ; \mathrm{CV}=2,2 \%)$. Os valores médios para os genótipos V2000, M737 e Contiflor 3 foram $755,6,832,4$ e $761,9 \mathrm{~kg} / \mathrm{m}^{3}$, respectivamente. O M737 superou os demais genótipos $(\mathrm{P}<0,05)$, fato provavelmente associado ao seu maior conteúdo de umidade. Não foram encontradas diferenças ( $\mathrm{P}>0,05)$ entre os tipos de silos. As densidades médias para os silos A, B e C foram 774,6, 788,7, $786,7 \mathrm{~kg} / \mathrm{m}^{3}$, respectivamente. Isso evidencia a padronização da compactação das silagens e permite comparar os demais parâmetros.

Os dados referentes aos teores de PB nas silagens encontram-se na Tab. 2. Foi observada interação significativa $(\mathrm{P}<0,05)$ entre o tipo de silo e o genótipo. V2000 apresentou os maiores valores $(\mathrm{P}<0,05)$ seguido pelo M737 e Contiflor 3 para as silagens obtidas nos tipos de silo B e C. No silo A, o genótipo Contiflor 3 foi inferior aos demais $(\mathrm{P}<0,05)$. $\mathrm{O}$ tipo de silo somente influenciou o conteúdo de proteína bruta para o genótipo V2000. O menor valor de PB foi para as silagens obtidas no silo $A$, o que, provavelmente, está relacionado com a maior degradação de proteína ocorrida nesse silo, propiciada pela maior umidade, já que esse não apresentava compartimento para o escape dos efluentes. As porcentagens médias de PB observadas para os três genótipos de girassol foram próximas ao valor médio de $9,1 \%$ obtido por Tomich et al. (2003), que avaliaram 13 genótipos de girassol.
Tabela 2. Proteína bruta (\% da matéria seca da silagem) de três genótipos de girassol obtidos em três tipos de silos experimentais

\begin{tabular}{lcccc}
\hline Silo & V2000 & M737 & Contiflor 3 & Média \\
\hline $\mathrm{A}$ & $9,38 \mathrm{Ba}$ & $9,51 \mathrm{Aa}$ & $8,00 \mathrm{Ab}$ & 8,96 \\
$\mathrm{~B}$ & $10,68 \mathrm{Aa}$ & $9,35 \mathrm{Ab}$ & $8,52 \mathrm{Ac}$ & 9,52 \\
$\mathrm{C}$ & $10,93 \mathrm{Aa}$ & $9,06 \mathrm{Ab}$ & $8,45 \mathrm{Ac}$ & 9,47 \\
Média & 10,33 & 9,31 & 8,32 & \\
\hline
\end{tabular}

Valores seguidos por letras maiúsculas distintas na mesma coluna ou letras minúsculas distintas na mesma linha diferem entre si $(\mathrm{P}<0,05) ; \mathrm{CV}=3,5 \%$, interação: tipo de silo $\mathrm{x}$ genótipo $(\mathrm{P}<0,05)$.

$\mathrm{O}$ conteúdo de $\mathrm{N}-\mathrm{NH}_{3} / \mathrm{NT}$ é um indicativo da degradação da proteína durante o processo de ensilagem. Não foi observada interação $(\mathrm{P}>0,05)$ tipo de silo versus genótipo $(\mathrm{CV}=5,9 \%)$. Entre os genótipos, o V2000 apresentou o valor mais elevado $(12,5 \%)$, independente do tipo de silo. Os genótipos M737 (7,6\%) e Contiflor $3(7,4 \%)$ foram semelhantes $(\mathrm{P}>0,05)$. Esses valores estão dentro da faixa de variação de 5,9 a 15,8 \% observados por Noguera (2000) e Tomich et al. (2003). Quando se compararam os tipos de silos para os diferentes genótipos, observou-se que as porcentagens de $\mathrm{N}-\mathrm{NH}_{3} / \mathrm{NT}$ foram equivalentes $(\mathrm{P}>0,05)$ para as silagens dos silos $\mathrm{B}(8,5 \%)$ e $\mathrm{C}$ $(8,5 \%)$ e menores para a silagem do silo $\mathrm{A}$ $(10,4 \%)$, indicando menor hidrólise de proteínas e degradação de aminoácidos.

Quanto ao $\mathrm{pH}$, não se observou interação $(\mathrm{P}>0,05)$ tipo de silo versus genótipo. $\mathrm{O}$ coeficiente de variação do $\mathrm{pH}$ foi de $2,8 \%$. Houve variação entre os genótipos, sendo o maior valor $(\mathrm{P}<0,05)$ obtido para o V2000 $(5,0)$, seguido do Contiflor $3(4,5)$ e M737 (4,1). Nenhuma das silagens apresentou valores de $\mathrm{pH}$ entre 3,6 e 3,8, que classificariam as silagens como de muito boa qualidade, segundo o critério proposto por Paiva (1976). Porém, os valores mais elevados são normais para a silagem de girassol, pois essa planta apresenta elevado poder tampão (Tosi et al., 1975) e baixa relação de açúcar/proteína, devido aos elevados valores de PB. Na comparação entre os silos, não foram observadas diferenças $(\mathrm{P}>0,05)$, e os valores foram 4,6, 4,5 e 4,5 para os silos A, B e C, respectivamente.

Para $\mathrm{CHO}$, a interação tipo de silo versus genótipo não foi significativa $(\mathrm{P}>0,05 ; \mathrm{CV}=$ $16,9 \%)$. Houve diferença entre as silagens produzidas nos silos tipo A quando comparadas 
com os valores das silagens dos silos $\mathrm{B}(0,08 \%)$ e C $(0,09 \%)$, que se equivaleram $(\mathrm{P}>0,05)$ e apresentaram valores inferiores $(\mathrm{P}<0,05)$ aos do silo A. Esse resultado deve-se, possivelmente, à presença do compartimento de areia nos silos B e $\mathrm{C}$, que possibilitaria o escoamento dos efluentes, com possível carreamento dos $\mathrm{CHO}$, diminuindo os teores finais nas silagens, ou teria criado condições de fermentação mais favoráveis, já que foram observados maiores valores de MS para silagens obtidas nos silos B e C. O genótipo V2000 apresentou os menores valores $(0,08 \%$; $\mathrm{P}<0,05)$ quando comparado aos genótipos M737 $(0,19 \%)$ e Contiflor $3(0,15 \%)$, que foram semelhantes entre si $(\mathrm{P}>0,05)$. Essa diferença pode ser atribuída aos menores valores observados no material original, isto é, $1,0 \%$ para o V2000 e 4,4 e 2,4\% para M737 e Contiflor 3, respectivamente. A fração de $\mathrm{CHO}$ é a principal fonte de substrato para a fermentação no silo, o que pode ser confirmado pelos valores reduzidos encontrados nas silagens deste trabalho, independente do tipo de silo ou genótipo avaliado.

Não foi observada interação tipo de silo versus genótipo $(\mathrm{P}>0,05)$ para os conteúdos de LAT e $\mathrm{ACE}(\mathrm{CV}=8,4 ; 13,1 \%$, respectivamente $)$. Entre genótipos, o maior conteúdo de LAT $(\mathrm{P}<0,05)$ obtido foi para o M737 (15,0\%), seguido do Contiflor $3(9,8 \%)$ e V2000 (7,4\%). Para o ACE, no V2000 o valor foi $3,0 \%$, superior $(\mathrm{P}<0,05)$ aos 2,3 e 2,6\% encontrados para os genótipos M737 e Contiflor 3, respectivamente. Os tipos de silo influenciaram os valores de LAT e ACE. Foi encontrada maior produção de LAT $(\mathrm{P}<0,05)$ para os silos B $(11,4 \%)$ e C $(12,2 \%)$ quando comparados com o silo A. Essa maior produção de LAT pode estar relacionada à melhor condição de fermentação propiciada pelo compartimento para escape de efluentes que favoreceu o crescimento de bactérias ácidoláticas. Para o ACE, o menor valor $(\mathrm{P}<0,05)$ foi para o tipo $\mathrm{A}(2,2 \%)$, enquanto os silos $\mathrm{B}(2,7 \%)$ e $\mathrm{C}(2,9 \%)$ foram semelhantes entre si $(\mathrm{P}>0,05)$. A presença do ACE é indesejável, e teores acima de $2 \%$ podem reduzir o consumo da silagem pelos animais (McDonald et al., 1991).

Os valores de BUT encontram-se na Tab. 3. Para os genótipos M737 e Contiflor 3 nos três tipos de silos e para o V2000 na silagem no silo C, foram observados apenas traços desse ácido, o que mostra a baixa atividade de bactérias do gênero Clostridium nos processos fermentativos. Na comparação dos tipos de silos, foram encontradas diferenças apenas para o genótipo V2000. Os teores de BUT para o silo A foram semelhantes $(\mathrm{P}>0,05)$ aos do silo $\mathrm{B}$ e superiores $(\mathrm{P}<0,05)$ aos da silagem obtida com o silo $\mathrm{C}$.

Tabela 3. Teores de ácido butírico (\% da matéria seca) das silagens de três genótipos de girassol obtidos em três tipos de silos experimentais

\begin{tabular}{lcccc}
\hline Silo & V2000 & M737 & Contiflor 3 & Média \\
\hline $\mathrm{A}$ & $0,28 \mathrm{Aa}$ & $0,00 \mathrm{Ab}$ & $0,00 \mathrm{Ab}$ & 0,09 \\
$\mathrm{~B}$ & $0,17 \mathrm{Aa}$ & $0,00 \mathrm{Ab}$ & $0,07 \mathrm{Ab}$ & 0,08 \\
$\mathrm{C}$ & $0,00 \mathrm{Ba}$ & $0,00 \mathrm{Aa}$ & $0,00 \mathrm{Aa}$ & 0,00 \\
Média & 0,15 & 0,00 & 0,02 & \\
\hline
\end{tabular}

Valores seguidos por letras maiúsculas distintas na mesma coluna ou letras minúsculas distintas na mesma linha diferem entre si $(\mathrm{P}<0,05) ; \mathrm{CV}=39,5 \%$; interação: tipo de silo $\times$ genótipo $(\mathrm{P}<0,05)$.

Para as frações fibrosas, a interação tipo de silo versus genótipo não foi significativa $(\mathrm{P}>0,05)$. $\mathrm{Na}$ Tab. 4 encontram-se os valores de FDN, FDA, celulose, hemicelulose e lignina das silagens dos três genótipos de girassol (média dos três tipos de silos). Os genótipos M737 e V2000 foram semelhantes entre si $(\mathrm{P}>0,05)$ para as frações celulose e hemicelulose, enquanto o Contiflor 3 apresentou os valores mais elevados $(\mathrm{P}<0,05)$ para todas as frações estudadas.

Tabela 4. Concentrações de fibra detergente neutro (FDN), fibra detergente ácido (FDA), celulose, hemicelulose e lignina ( $\%$ da matéria seca) das silagens dos três genótipos de girassol

\begin{tabular}{lccc}
\hline & \multicolumn{3}{c}{ Genótipos } \\
\cline { 2 - 4 } & V2000 & M737 & Contiflor 3 \\
\hline FDN & $44,47 \mathrm{~b}$ & $42,55 \mathrm{c}$ & $48,40 \mathrm{a}$ \\
FDA & $34,47 \mathrm{~b}$ & $32,65 \mathrm{c}$ & $37,14 \mathrm{a}$ \\
Celulose & $27,72 \mathrm{~b}$ & $26,55 \mathrm{~b}$ & $29,65 \mathrm{a}$ \\
Hemicelulose & $10,00 \mathrm{~b}$ & $9,90 \mathrm{~b}$ & $11,27 \mathrm{a}$ \\
Lignina & $6,76 \mathrm{~b}$ & $6,10 \mathrm{c}$ & $7,48 \mathrm{a}$ \\
\hline
\end{tabular}

Valores seguidos por letras minúsculas distintas na mesma linha diferem entre si $(\mathrm{P}<0,05) ; \mathrm{FDN}$ : $\mathrm{CV}=3,8 \%$; FDA: $\mathrm{CV}$ $=4,4 \%$; celulose: $\mathrm{CV}=4,8 \%$; hemicelulose: $\mathrm{CV}=5,4 \%$; lignina: $\mathrm{CV}=4,9 \%$.

$\mathrm{Na}$ Tab. 5, encontram-se os valores de FDN, FDA, celulose, hemicelulose e lignina das silagens obtidas nos três tipos de silos (média dos três genótipos). Não foram observadas diferenças para as frações FDA e celulose, enquanto as 
frações FDN, hemicelulose e lignina das silagens obtidas no silo tipo A apresentaram valores inferiores às obtidas nos silos $\mathrm{B}$ e $\mathrm{C}(\mathrm{P}<0,05)$. As variações observadas não permitiram concluir se os tipos de silos avaliados foram os responsáveis pelas diferenças encontradas.

Tabela 5. Concentrações de fibra detergente neutro (FDN), fibra detergente ácido (FDA), celulose, hemicelulose e lignina (\% da matéria seca) das silagens obtidas nos três tipos de silos

\begin{tabular}{lccc}
\hline & \multicolumn{3}{c}{ Tipo de silo } \\
\cline { 2 - 4 } & $\mathrm{A}$ & $\mathrm{B}$ & $\mathrm{C}$ \\
\hline FDN & $43,64 \mathrm{~B}$ & $46,02 \mathrm{~A}$ & $45,77 \mathrm{~A}$ \\
FDA & $33,90 \mathrm{~A}$ & $35,37 \mathrm{~A}$ & $34,99 \mathrm{~A}$ \\
Celulose & $27,53 \mathrm{~A}$ & $28,30 \mathrm{~A}$ & $28,10 \mathrm{~A}$ \\
Hemicelulose & $9,74 \mathrm{~B}$ & $10,65 \mathrm{~A}$ & $10,78 \mathrm{~A}$ \\
Lignina & $6,38 \mathrm{~B}$ & $7,06 \mathrm{~A}$ & $6,90 \mathrm{~A}$ \\
\hline
\end{tabular}

Valores seguidos por letras maiúsculas distintas na mesma linha diferem entre si $(\mathrm{P}<0,05)$; $\mathrm{FDN}$ : $\mathrm{CV}=3,8 \%$; FDA: $\mathrm{CV}$ $=4,4 \%$; celulose: $\mathrm{CV}=4,8 \%$; hemicelulose: $\mathrm{CV}=5,4 \%$; lignina: $\mathrm{CV}=4,9 \%$.

Os valores de DIVMS encontrados na Tab. 6 oscilaram de 47,1\%, para a silagem do V2000 obtida no tipo de silo $\mathrm{C}$, a $56,7 \%$, para a silagem do M737, obtida no tipo de silo A. Na avaliação entre genótipos, o M737 apresentou os valores mais altos $(\mathrm{P}<0,05)$ quando comparado aos demais. $\mathrm{Na}$ comparação entre tipos, apenas o Contiflor 3 não apresentou diferenças $(\mathrm{P}>0,05)$, enquanto as diferenças observadas para os genótipos V2000 e M737 não evidenciaram a superioridade de um sobre o outro.

Tabela 6. Digestibilidade in vitro da matéria seca (\% da matéria seca) das silagens de três genótipos de girassol, obtidos em três tipos de silos experimentais

\begin{tabular}{lcccc}
\hline Silo & V2000 & M737 & Contiflor 3 & Média \\
\hline $\mathrm{A}$ & $48,86 \mathrm{Ab}$ & $56,68 \mathrm{Aa}$ & $49,90 \mathrm{Ab}$ & 51,48 \\
$\mathrm{~B}$ & $50,19 \mathrm{Ab}$ & $53,72 \mathrm{Ba}$ & $48,16 \mathrm{Ac}$ & 50,69 \\
$\mathrm{C}$ & $47,06 \mathrm{Bb}$ & $52,87 \mathrm{Ba}$ & $48,81 \mathrm{Ab}$ & 49,58 \\
Média & 48,70 & 54,43 & 48,62 & \\
\hline
\end{tabular}

Valores seguidos por letras maiúsculas distintas na mesma coluna ou letras minúsculas distintas na mesma linha diferem entre si $(\mathrm{P}<0,05) ; \mathrm{CV}=2,0 \%$; interação: tipo de silo $\mathrm{x}$ genótipo $(\mathrm{P}<0,05)$.

A classificação da qualidade das silagens, segundo os critérios adotados por Meyer et al. (1989), encontra-se na Tab. 7.
Tabela 7. Classificação das silagens* dos três genótipos de girassol, obtidas em três tipos de silos experimentais

\begin{tabular}{lccc}
\hline Silo & V2000 & M737 & Contiflor 3 \\
\hline A & Média & Muito boa & Muito boa \\
B & Boa & Muito boa & Muito boa \\
C & Boa & Muito boa & Muito boa \\
\hline$*$ Critérios propostos & por Meyer et al. (1989)
\end{tabular}

O tipo de silo influenciou a classificação apenas do genótipo V2000, que apresentou silagens de boa qualidade para os tipos de silo B e C e média para o silo A. Para o M737 e Contiflor 3, as silagens foram de muito boa qualidade para os três tipos de silos. A qualidade das silagens dos genótipos M737 e Contiflor 3 foi sempre superior à do V2000.

\section{CONCLUSÕES}

Silagens de girassol com baixo conteúdo de MS podem ter a qualidade e o valor nutritivo afetado pelo tipo de silo de laboratório utilizado. A válvula de Bunsen não influenciou a qualidade e o valor nutritivo das silagens dos genótipos estudados.

\section{REFERÊNCIAS BIBLIOGRÁFICAS}

BAILEY, R.W. Quantitative studies of ruminant digestion. II. Loss of ingested plant carbohydrates from the reticulo rumen. New Zeal. J. Agric. Res., v.10, p.15-32, 1967.

ELFERINK, S.J.W.H.O.; DRIRHUIS, F.; GOTTSCHL. J.C. et al. Silage fermentation process and their manipulation. In: SILAGE MAKING IN THE TROPICS WITH PARTICULAR EMPHASIS ON SMALLHOLDERS, 1999, Roma. Proceedings... Roma: FAO, 2000. p.17-31.

FREIRE, E.M. Padrão de fermentação das silagens de cinco híbridos de girassol. 2001. 44f. Dissertação (Mestrado em Zootecnia) - Escola de Veterinária, Universidade Federal de Minas Gerais, Belo Horizonte.

HARGREAVES, A.B.; BUTENDIECK, B.N.; HIRIRART, L.M. Comparacion de dos silos experimentales para la investigacion de ensilajes. Agric. Tec., v.45, p.185-191, 1986. 
McDONALD, P.; HENDERSON, A. R.; HERON, S. The biochemistry of silage. 2.ed. Marlow: Chalcombe Publications, 1991. 340p.

NOGUERA, J.R.R. Qualidade de silagens de quatro cultivares de girassol ensilados com diferentes proporções da planta. 2000. 34f. Dissertação (Mestrado em Zootecnia) - Escola de Veterinária, Universidade Federal de Minas Gerais, Belo Horizonte.

OFFICIAL methods of analysis. 16.ed. Washington, DC: AOAC, 1995. 2000p.

PAIVA, J.A.J. Qualidade da silagem da região metalúrgica de Minas Gerais. 1976. 85f. Dissertação (Mestrado em Zootecnia) - Escola de Veterinária, Universidade Federal de Minas Gerais, Belo Horizonte.

PERKINS, A.E.; PRATT, A.D. A laboratory silo and its uses. J. Dairy Sci., v.34, p.606-614, 1951.

REZENDE, A.V. Avaliação do potencial do girassol (Helianthus annuus L.) como planta forrageira para silagem e para associar-se ao capim-elefante (Pennisetum purpureum SCHUM.) na ensilagem. 2001. 116f. Tese (Doutorado em Zootecnia) - Universidade Federal de Lavras, Lavras, MG.
TILLEY, J.M.A.; TERRY, R.A. A two-stage technique for the in vitro digestion of forage crops. J. Br. Grassl. Soc., v.18, p.104-111, 1963.

TOMICH, T.R.; RODRIGUES, J.A.S.; GONÇALVES, L.C. et al. Potencial forrageiro de cultivares de girassol produzidos na safrinha para ensilagem. Arq. Bras. Med. Vet. Zootec., v.55, p.756-762, 2003.

TOSI, H.; SILVEIRA, A.C.; FARIA, V.P. et al. Avaliação do girassol (Helianthus annuus) como planta para a ensilagem. Rev. Soc. Bras. Zootec., v.4, p.39-48, 1975.

VALADARES FILHO, S.C.; ROCHA JUNIOR, V.R.; CAPPELLE, E.R. Tabelas brasileiras de composição de alimentos para bovinos CQBAL 2.0. Viçosa: Suprema, 2002. 297p.

VAN SOEST, P.J.; ROBERTSON, J.B.; LEWIS, B.A. Methods for dietary fiber, neutral detergent, and nonstarch polysaccharides in relation to animal nutrition. J. Dairy Sci., v.74, p.35833597, 1991.

XICCATO, G., CINETTO, M., CARAZZOLO, A. et al. The effect of silo type dry matter content on the maize silage fermentation process and ensiling loss. An. Feed Sci. Technol., v.49, p.311-323, 1994. 